Canadian

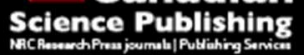

Botany

Botanique

\title{
Reliability of leaf relative water content (RWC) measurements after storage: consequences for in situ measurements
}

\begin{tabular}{|r|l|}
\hline Journal: & Botany \\
\hline Manuscript ID: & cjb-2015-0065.R1 \\
\hline Manuscript Type: & Methods \\
\hline Date Submitted by the Author: & 04-Jun-2015 \\
\hline Complete List of Authors: & $\begin{array}{l}\text { Tanentzap, Fallon; Laurentian University, Biology } \\
\text { Stempel, Alexandra; Laurentian University, Biology } \\
\text { Ryser, Peter; Laurentian University, Biology }\end{array}$ \\
\hline Keyword: & Field measurement, Plant Water Status, Relative Water Content \\
\hline
\end{tabular}

SCHOLARONE $^{\text {s" }}$

Manuscripts 
1 Reliability of leaf relative water content (RWC) measurements after storage:

2 consequences for in situ measurements

3

4 Fallon M. Tanentzap, Alexandra Stempel and Peter Ryser 5

6 Laurentian University, Department of Biology

7935 Ramsey Lake Road, Sudbury, Ontario, Canada, P3E 2C6

8

$9 \quad$ Email addresses: $\quad$ FMT: $\underline{\text { FX_Kirkey@laurentian.ca }}$

PR: PRyser@1aurentian.ca

12

13 Corresponding author:

14 P. Ryser, Laurentian University, Department of Biology, 935 Ramsey Lake Road,

15 Sudbury, Ontario, Canada, P3E 2C6

16 Phone: 1-705-675-1151 ext. 2353

17 Fax: 1-705-675-4859

18

19 


\section{Abstract}

21 Relative Water Content (RWC) is widely used to describe plant water status, and is

22 commonly measured gravimetrically. The ephemeral nature of leaf fresh mass poses

23 severe constraints for such measurements in field-grown plants. These constraints can be

24 overcome by transporting the leaves in waterproof containers into the lab. However, even

25 then leaves lose water, and other changes may happen. The effects of a delay on the

26 measurement of RWC have not been quantified so far. In this study the influence of

27 duration of storage up to 96 hours and storage temperature on RWC and its components

28 was investigated for four species. Alnus incana, Impatiens capensis, Scirpus microcarpus

29 leaves were stored in plastic bags, those of Comptonia peregrina in plastic vials. RWC

30 remained within $5 \%$ of the initial value during $24 \mathrm{~h}$ cool storage, but after that larger

31 changes were observed. The effects of storage were species specific, being most

32 pronounced in species poorly protected against desiccation, and under warm conditions.

33 The effects of storage were not only limited to water loss, but also included cellular

34 degradation. In general, storage at $10^{\circ} \mathrm{C}$ for $24 \mathrm{~h}$ enables measurement of RWC for field-

35 grown plants with accuracy of a few percent, but care has to be taken with species

36 vulnerable to desiccation, possibly requiring faster measurement and a cooler storage

37 temperature.

40 Key Words: Field measurement; Plant Water Status; Relative Water Content 


\section{Introduction}

42 Leaf Relative Water Content (RWC) is commonly used to describe plant water

43 status at a given time (Stocker 1929; Barrs 1968; Kramer 1969). It is a sensitive variable,

44 which quickly responds to environmental conditions such as temperature, light, humidity

45 and water supply (Slatyer 1962). RWC correlates closely with a plant's physiological

46 activities and soil water status (Munne-Bosch and Penuelas 2004; Ozkur et al. 2009), and

47 is a reliable trait, e.g., for screening for drought tolerance of different genotypes

48 (Rachmilevitch et al. 2006). It is defined as the percentage of water present at the time of

49 sampling, relative to the amount of water in a saturated leaf, calculated as

$50 \quad \mathrm{RWC}(\%)=100 \times(\mathrm{FM}-\mathrm{DM}) /(\mathrm{SM}-\mathrm{DM})$

51 where FM is leaf fresh mass at the time of collection, SM is leaf mass at saturated

52 condition, and DM is leaf dry mass (Turner 1981). During recent years progress has been

53 made in methods to measure plant water status non-invasively using foliar reflectance

54 (e.g., Jördens et al. 2009; Cheng et al. 2012), but such a method is currently not easily

55 available for a wide use, especially for field investigations (Sancho-Knapik et al. 2013).

56 The gravimetric method that has been described as optimal with respect to reliability and

57 simplicity (Lösch 2001), remains widely used (Fernández-García et al. 2014; Jolly et al.

58 2014; Liu et al. 2014; Thameur et al. 2014; Chimungu et al. 2015, Gorai et al. 2015;

59 Yang et al. 2015).

60 Accurate measurement of the different leaf masses is not trivial (Rachmilevitch et

61 al. 2006). Measurement of the saturated mass, commonly achieved by floating leaf discs

62 on water, has received considerable attention (Weatherley 1950; Barrs 1968; Smart and

63 Bingham 1974; Gonzalez and Gonzalez-Vilar 2001) and protocols to saturate leaves in 
64 large-scale comparative measurements of field-grown plants have recently been

65 described (Garnier et al. 2001; Ryser et al. 2008). On the other hand, constraints

66 influencing measurement of the initial fresh mass have received less attention, as in most

67 of the studies leaf relative water content has been assessed in the laboratory or

68 greenhouse, where fresh mass of the collected leaves can immediately be measured. In

69 the field, however, the quick loss of water from excised leaves poses a problem, requiring

70 protective measures against water loss. Tin cans (Stocker 1929; Jolly et al. 2014), plastic

71 vials (Hadley and Smith 1983; Armas et al. 2010; Aref et al. 2013; Fernández-García et

72 al. 2014) and sealed plastic bags (Smart and Bingham 1974; Gonzalez and Gonzalez-

73 Vilar 2001; Davidson et al. 2006; Gonçalves et al. 2011; Ryser et al. 2011; Walter et al.

74 2011; Teszlák et al. 2013) have been used to protect the collected leaves against water

75 loss during the transportation from field to laboratory. Govender et al. (2009) stress the

76 importance of a proper sampling procedure to prevent water loss by keeping leaves in

77 plastic bags and in a cool dark place. Possible changes in RWC during storage have been

78 tested by Hadley and Smith (1983) and Breashers et al. (1997) for conifer needles, but

79 sensitivity of less robust leaves than conifer needles has not been tested. Many

80 publications do not even describe how and for how long the leaves are stored between

81 excision and fresh mass measurement.

82 The purpose of this investigation is to determine constraints of accurate

83 gravimetric measurements of RWC in the field, considering changes induced by the

84 unavoidable delay in the measurement on leaf fresh mass, but also on other traits. The

85 effects of the duration and conditions of the delay on water loss have never been

86 quantified, neither other aspects potentially affecting the accuracy of the calculation of 
87 RWC. Such aspects are cellular respiration (Gonzalez and Gonzalez-Vilar 2001;

88 Rachmilevitch et al. 2006), which may decrease leaf dry mass during storage at warm

89 temperatures, and membrane deterioration, which influences water content at saturation

90 (Deschene et al. 1991).

91 For storage we used primarily re-sealable plastic bags. Plastic bags are frequently

92 used for this purpose, but they are not impermeable to gases, and a slow diffusion of

93 water molecules through plastic will lead to loss of water over time. However, compared

94 to microcentrifuge tubes with lower diffusion rates, bags enable collection of large leaves

95 with a minimal use of space. We assess changes caused by transportation delay by

96 investigating the effects of both duration and temperature of storage on leaves of three

97 species with contrasting vulnerability to water loss in order to establish a guideline for

98 large-scale in situ RWC measurements. Additionally, we also investigate the effect of

99 storage in microcentrifuge tubes on one species with small leaves. We will assess for how

100 long leaves can be stored for the measured values of RWC remaining accurate, and how

101 important a cool temperature during the storage is. It has been shown that cool storage of

$1021 \mathrm{~h}$ or $48 \mathrm{~h}$ does not influence the measured RWC of desiccation-resistant leaves such as

103 conifer needles (Hadley and Smith 1983; Breashers et al. 1997), but the effects of

104 duration and temperature of storage on leaves of a wider variety of species has not been

105 investigated. Additionally to the effect of storage, we test the logistic feasibility of the

106 method by measuring the daily course of leaf RWC of two species in a real field

107 situation, so far away from the lab that the weight measurements could be conducted only

108 the following day. 


\section{Materials and methods}

111 Leaf collection sites and species used

112 Two experiments were conducted to test the reliability of RWC measurements when

113 immediate measurement of leaf fresh mass is not possible. In both experiments, leaf

114 samples were collected within Laurentian University Campus (46²7'59”N 8058'23” W)

115 in Sudbury, Ontario, Canada. Three species with contrasting leaf characteristics and

116 vulnerability to desiccation were selected to be stored in plastic bags: Impatiens capensis

117 Meerb. (Balsaminaceae), Scirpus microcarpus J. Presl \& C. Presl (Cyperaceae) and Alnus

118 incana ssp. rugosa (Du Roi) R. T. Clausen (Betulaceae). Additionally, storage effects in

119 microcentrifuge tubes were tested using a fourth species with small leaves, Comptonia

120 peregrina (L.) J. M. Coulter (Myricaceae). The annual herb I. capensis occurs under

121 shady and wet conditions and is extremely poorly protected against desiccation, whereas

122 C. peregrina, a dwarf shrub of exposed rocky sites is well protected against water loss. $A$.

123 incana is a small tree forming dense canopies in swamps, and the graminoid $S$.

124 microcarpus grows on open moist conditions. I. capensis and C. peregrina reflect

125 extremes of vulnerability to desiccation across the species at the collection site.

126 Desiccation speed for the leaves of the four species was tested by laying them for one

127 hour unprotected on a lab counter at about $27^{\circ} \mathrm{C}$. During this hour, I. capensis lost $62 \pm 5 \%$

128 of its leaf fresh mass, $A$. incana $13 \pm 0 \%, S$. microcarpus $10 \pm 2 \%$. and C. peregrina $5 \pm 1 \%$

129 (mean $\pm 1 \mathrm{SE} ; \mathrm{N}=6)$.

130 Experiment 1

131 In this experiment the change in leaf fresh mass due to loss of water during storage was

132 documented over periods of up to $96 \mathrm{~h}$. The storage containers should protect leaves 
133 against desiccation, but also be light enough to avoid exceeding the capacity of high-

134 precision balances. For the species with the smallest leaves we used microcentrifuge

135 tubes, and for larger leaves small re-sealable plastic bags.

136 Branches or shoots from each of the four species were collected and placed in a

137 large plastic bag in the field on 23 July 2012, 9:00 a.m., and brought within 15 min to the

138 lab, where they were placed in water-filled beakers. For three species, twenty fresh leaves

139 were collected per species, weighed and placed into pre-weighed resealable $10 \times 15 \mathrm{~cm}$

$1400.05 \mathrm{~mm}$ (2 mil) plastic polybags (WAT supplies, Sudbury, ON, Canada). For $C$.

141 peregrina, the species with the smallest leaves, $1.5 \mathrm{~mL}$ Fisherbrand ${ }^{\mathrm{TM}}$ Premium

142 microcentrifuge tubes were used. All the bags and tubes with leaves were weighed and

143 the values recorded as values at time zero. The bags and tubes were then put in sealed

144 plastic containers for storage. Half the samples were stored at room temperature, average

145 temperatures during the 4 days of the experiment being $29,28,27$, and $26^{\circ} \mathrm{C}$,

146 respectively (iButton dataloggers DS1921G; Maxim Integrated, San Jose, California).

147 The other half of the bags were placed in a refrigerator with a temperature of $10^{\circ} \mathrm{C}$. All

148 bags with leaves were re-weighed after 3, 6, 24, 48 and $96 \mathrm{~h}$ after the first measurement.

149 Leaf fresh mass at the time of measurement was calculated by deducting the bag mass

150 from the measured mass of the bag with leaf. This value was then normalized by dividing

151 it by the initial, pre-bagging leaf mass, enabling a direct comparison of relative fresh

152 mass changes of all the leaves.

153 Experiment 2

154 In this experiment changes in leaf RWC, leaf fresh mass to saturated mass ratio, and leaf 155 dry mass to saturated mass ratio were documented after storage in plastic bags (3 species) 
156 or microcentrifuge tubes ( 1 species) after $24 \mathrm{~h}$ and after $96 \mathrm{~h}$, by comparing the values to

157 the initial measurements. RWC is the target variable, which is calculated using leaf fresh

158 mass, leaf saturated mass and leaf dry mass (leaf dry matter content). The fresh mass to

159 saturated mass, and the dry mass to saturated mass ratios indicate how the components of

160 RWC contribute to its change.

161 As saturated mass and dry mass of the stored leaves could not be repeatedly

162 measured, each measurement required a separate set of leaves. On 24 July 2012, 9:00

163 a.m. 240 leaves were harvested on campus. Sixty leaves from each of the four species

164 were collected directly into resealable bags or microcentrifuge tubes (C. peregrina). The

165 bagged samples were transported in a cooler to the lab within one hour. Two thirds of the

166 bags containing the leaves were then stored in airtight plastic boxes either in a

167 refrigerator $\left(10.0^{\circ} \mathrm{C}\right)$ or at room temperature (averages for the 4 days of the experiment:

$16828,27,26$, and $25^{\circ} \mathrm{C}$, respectively). For one third of the leaves their fresh mass was

169 immediately measured, for another third after $24 \mathrm{~h}$ storage, and for the last third after 96

$170 \mathrm{~h}$ storage. After the measurement of fresh mass, the leaves were placed in a refrigerator

171 between moist paper towels for $24 \mathrm{~h}$ to attain saturation (Ryser et al. 2008). Leaf

172 saturated mass was measured, after which the leaves were dried at $75^{\circ} \mathrm{C}$ for $48 \mathrm{~h}$, and

173 their dry mass determined.

174 Field measurements of $R W C$

175 To test the practicality of the method under a real field situation, diurnal fluctuation of

176 leaf RWC was measured for two species, Bidens cernua L. (Asteraceae) and Carex

177 retrosa Schwein. (Cyperaceae) in a wetland $40 \mathrm{~km}$ from the lab. Leaves of these two

178 species were collected on five occasions from dawn to dusk $(6: 30,10: 00,14: 00,18: 00$, 
$17920: 00)$ on 9 September 2012, with 10 replicate leaves at a time into pre-weighed

180 resealable plastic bags. The bagged samples were placed inside a cooler $\left(7-10^{\circ} \mathrm{C}\right)$ and

181 brought to the laboratory the following day. Leaf fresh mass, saturated mass and dry mass

182 were measured as described for Experiment 2.

184 Results

185 Experiment 1

186 Leaves of all species lost water during storage in plastic bags, and the loss was faster at

187 room temperature than in the refrigerator (Fig. 1; Table 1). For C. peregrina leaves, the

188 species best protected against desiccation and the only species stored in microcentrifuge

189 tubes, there was a slight but non-significant decrease in fresh mass, especially under the

190 warm storage temperature. After $24 \mathrm{~h}$ in the refrigerator, I. capensis leaves had lost $7 \%$ of

191 their fresh mass. For the other three species the loss did not exceed $2 \%$. At room

192 temperature, fresh mass declined faster, but the loss during the first $24 \mathrm{~h}$ remained for all

193 species except I. capensis below $6 \%$ of the original value. Even after $96 \mathrm{~h}$ in the

194 refrigerator leaves of three of the four species lost at most $6 \%$ of their fresh mass. $I$.

195 capensis was the most vulnerable with 17\% loss. Under warm conditions, I. capensis

196 leaves lost $62 \%$ of their fresh mass within $96 \mathrm{~h}$.

197 Experiment 2

198 Calculated values for leaf relative water content decreased during prolonged storage for

199 all species (Fig. 2; Table 1). The decline was faster under warm conditions. Under cool

200 conditions, the RWC values lost after $24 \mathrm{~h}$ at most $5 \%$ of the initial values (I. capensis, $A$.

201 incana), under warm conditions at most 12\% (I. capensis, A. rugosa, S. microcarpus). 
202 After 96 h, RWC had further declined, except for warm-stored A. incana and $C$.

203 peregrina leaves, for which RWC increased between 24 and 96 h. In ANOVA's

204 conducted for each species, time had a significant effect on RWC for all species but $C$.

205 peregrina, the interaction with storage temperature being significant for I. capensis and $S$.

206 microcarpus (Table 1). Changes in the fresh mass to saturated mass ratio were close to

207 those of RWC, but dry mass to saturated mass ratio (leaf dry matter content) showed a

208 different behavior (Fig. 2). In all species but S. microcarpus there was a significant Time

$209 \times$ Temperature interaction (Table 1). In case of $A$. incana, the ratio increased in the cold

210 and the warm treatment already after 24 h. For C. peregrina an increase was observed in

211 warm treatment only, for I. capensis in the cold treatment after $96 \mathrm{~h}$. We are not aware of

212 any mechanism to explain an increase of dry mass of leaves stored in cool and dark, and

213 consequently, the increased dry mass to saturated mass ratio seems to indicate a

214 decreased ability of the leaves to absorb water at saturating conditions, probably due to

215 changes at cellular level.

216 Field measurements of $R W C$

217 Both B. cernua and C. retorsa showed a significant diurnal variation in their RWC, the

218 values declining from the $99 \pm 1 \%$ and $96 \pm 1 \%$ at $6: 30$, respectively, down to $94 \pm 1 \%$ and

$21987 \pm 2 \%$ by $18: 00$, but rising again to $98 \pm 1 \%$ and $95 \pm 2 \%$ by $20: 00$ (mean values \pm 1 SE).

220 C. retrorsa had throughout lower values of RWC than B. cernua. Compared to the

221 diurnal variation and interspecific differences the standard error was small. Error

222 variation in C. retrorsa, the species with a larger diurnal variation, increased during the

223 day, indicating that the variation in RWC values was mainly caused by local variation

224 rather than changes during storage. The effects of species $(\mathrm{p}<0.001)$ and time $(\mathrm{p}<0.001)$ 
225 were highly significant, their interaction not $\left(\mathrm{R}^{2}=0.467\right.$, ANOVA, $\mathrm{N}=10$, one outlier with

226 a studentized residual $>5$ removed).

227

228 Discussion

229 The method of maintaining leaf fresh mass until measurement has to be functional

230 allowing a large number of replicates of field-collected samples to be measured over a

231 short time period. Re-sealable plastic bags are frequently used to store leaves of field-

232 grown plants until leaf water content can be assessed, but potential measurement errors

233 caused by water loss from leaves stored in such bags have not previously been quantified.

234 Our laboratory results show that in cool storage, RWC was maintained within 5\% of the

235 initial value for at least $24 \mathrm{~h}$, indicating that use of such bags to transport leaves from the

236 field to the laboratory allows determination of leaf RWC of field-grown plants with

237 reasonable accuracy. Our field test complemented the laboratory experiments by showing

238 that the method is feasible for use in remote locations, and the results are precise enough

239 to distinguish diurnal and interspecific differences.

240 However, our results also clearly show that caution has to be exerted when

241 measurement of vulnerable species is delayed. Leaves of sensitive species, such as $I$.

242 capensis, lost $7 \%$ of their fresh mass within $24 \mathrm{~h}$ at $10^{\circ} \mathrm{C}$, and $A$. incana leaves showed

243 after similar storage an increased dry mass to fresh mass ratio. This shows that during

244 storage the leaves not only lost water, but the ability of some species to gain mass under

245 saturating conditions declined as well. This is an indication of changes at cellular level,

246 e.g., membrane degradation (Deschene et al. 1991), and the pronounced change in $A$.

247 incana indicates that this effect is species specific as well. Previously, the effect of delay 
248 in fresh mass measurement has been found to be non-significant for conifer needles

249 (Hadley and Smith 1983; Breashers et al. 1997), but our data shows that this is not

250 necessarily the case for all species. Hence, the constraints for the accuracy of the RWC

251 measurement in the field depends on type of the investigated habitat, species of moist

252 shady environments, for example, being more vulnerable to changes. Caution is also

253 needed when there is a delay in measurement of variables other than RWC, for example

254 leaf dry matter content.

255 Plastic bags will lose water through slow diffusion. Using less permeable

256 containers, such as metal and glass jars, or more robust plastic tubes, avoids or reduces

257 this problem, but large leaves require large containers and the required volume may

258 become difficult to keep cool. The mass of such containers may exceed the capacity of

259 the high-resolution balances needed to measure the leaf mass accurately. Removing

260 leaves from the container at weighing may lead to further loss of water, especially if any

261 has condensed in the walls of the container. Our data indicate hardly any water loss from

262 microcentrifuge tubes, but they are not conclusive as the species used in the tubes was the

263 one best protected against desiccation.

264 Temperatures in the cool storage in our experiment were around $10^{\circ} \mathrm{C}$, considered

265 to be realistic to achieve in the field to store a large amount of leaves. That temperature

266 was sufficient to achieve a reliable measurement of leaf RWC within 24 hours, but our

267 data indicates that for sensitive species lower temperatures would be preferable. The

268 increasing FM/DM ratio in C. peregrina after 96 hours indicates that at prolonged storage

269 a lower temperature would be preferable even when the leaves are stored in less

270 permeable containers, in order to avoid cellular degradation. 
271 We conclude emphasizing the well-known importance of a fast measurement of

272 leaf fresh mass, and if a delay is unavoidable, making sure to store the leaves in a cool

273 and well-protected container. In such a case it is important to note that the effects of

274 duration and temperature of the storage are species specific. For sensitive species, e.g.,

275 herbs from shady and moist environments, special attention should be given to minimize

276 the duration and temperature of the storage, and to storage container permeability. The

277 effect of storage should possibly be quantified for such species. But nevertheless, storage

278 up to $24 \mathrm{~h}$ in re-sealable plastic bags under temperatures up to $10^{\circ} \mathrm{C}$ does not compromise

279 the data quality, resulting for most species in changes of the obtained RWC values of

280 only a few percentages.

281

282 Acknowledgements

283 This research was funded by the Collaborative Research and Development grant from the

284 Natural Sciences and Engineering Research Council of Canada (NSERC) with Vale

285 Canada Ltd. and the Centre for Excellence in Mining Innovation (CRDPJ 372568-08).

\section{References}

288 Aref, I., El Atta H., El Obeid M., Ahmed A., Khan P., and Iqbal, M. 2013. Effect of water 289 stress on relative water and chlorophyll contents of Juniperus procera Hochst. ex 290 Endlicher in Saudi Arabia. Life Sci. J. 10(4): 681-685. doi:10.7537/j.issn.1097-

$291 \quad 8135$.


292 Armas, C., Padilla F.M., Pugnaire F.I., and Jackson, R.B. 2010. Hydraulic lift and

293 tolerance to salinity of semiarid species: consequences for species interactions.

294 Oecologia. 162(1): 11-21. doi: 10.1007/s00442-009-1447-1.

295 Barrs, H.D. 1968. Determination of water deficits in plant tissue. In Water Deficits and plant growth. Edited by T.T. Kozlowski. Academic Press, New York. pp. 235368.

298 Breashers, D.D., Myers O.B., Johnson S.R., Meyer C.W., and Martens, S.N. 1997. Differential use of spatially heterogeneous soil moisture by two semiarid woody species: Pinus edulis and Juniperus monosperma. J.Ecol. 85(3): 289-299. doi: $10.2307 / 2960502$.

Cheng, T., Rivard B., Sánchez-Azofeifa A. G., Féret J. B., Jacquemoud S., and Ustin S.L. 2012. Predicting leaf gravimetric water content from foliar reflectance across a range of plant species using continuous wavelet analysis. J. Plant Phys. 169(12) 1134-1142. dx.doi.org/10.1016/j.jplph.2012.04.006.

Chimungu, J.G., Maliro, M.F., Nalivata, P.C., Kanyama-Phiri, G., Brown, K.M., and Lynch, J.P. 2015. Utility of root cortical aerenchyma under water limited

310 Davidson, A., Wang, S., and Wilmshurst, J. 2006. Remote sensing of grasslandshrubland vegetation water content in the shortwave domain. Int. J. Appl. Earth Obs. 8(4), 225-236. doi:10.1016/j.jag.2005.10.002.

313 Deschene, A., Paliyath G., Lougheed E.C., Dumbroff E.B., and Thompson, J.E. 1991. Membrane deterioration during postharvest senescence of broccoli florets: 
modulation by temperature and controlled atmosphere storage. Postharvest Biol. Tec. 1(1): 19-31. doi: 10.1016/0925-5214(91)90016-5.

317 Fernández-García, N., Olmos, E., Bardisi, E., García-De la Garma, J., López-Berenguer, C., and Rubio-Asensio, J.S. 2014. Intrinsic water use efficiency controls the adaptation to high salinity in a semi-arid adapted plant, henna (Lawsonia inermis L.). J. Plant Phys. 171(5), 64-75. http://dx.doi.org/10.1016/j.jplph.2013.11.004.

321

Garnier, E., Shipley B., Roumet C., and Laurent, G. 2001. A standardized protocol for the determination of specific leaf area and leaf dry matter content. Funct. Ecol. 15(5): 688-695. doi:10.1046/j.0269-8463.2001.00563.x.

Gonçalves, W.G., Costa, A.C., Lima, D.P., Silva, A.A., and Megguer, C.A. 2011.

Membrane permeability and relative water content in physic nuts plants submitted to fast water deficit. Gl. Sci. Technol. 4(1). Available from http://rioverde.ifgoiano.edu.br/periodicos/index.php/gst/article/view/258/245 [accessed 26 February 2015].

Gonzalez, L., and Gonzalez-Vilar, M. 2001. Determination of relative water content. In Handbook of plant ecophysiology techniques. Edited by M. J. Reigosa Roger. Kluwer Academic Publishers, New York. pp. 207-212.

Gorai, M., Laajili, W., Santiago, L. S., and Neffati, M. 2015. Rapid recovery of photosynthesis and water relations following soil drying and re-watering is related to the adaptation of desert shrub Ephedra alata subsp. alenda (Ephedraceae) to arid environments. Environ. Exp. Bot. 109, 113-121. doi:10.1016/j.envexpbot.2014.08.011. 
337 Govender, M., Weiersbye I.M., Witkowski E.T.F., and Ahmed, F. 2009. Review of

338 commonly used remote sensing and ground-based technologies to measure plant

$339 \quad$ water stress. Water $S A$. 35: 741-752. Available from

340 http://www.ajol.info/index.php/wsa/article/view/76861/67333 [accessed 26

$341 \quad$ February 2015].

342 Hadley, J.L., and Smith, W.K. 1983. Influence of wind exposure on needle desiccation 343 and mortality for timberline conifers in Wyoming, USA. Arctic Alpine Res. 15:

344 127-135. Available from http://www.jstor.org/stable/1550988.

345 Jolly, W.M., Hadlow, A.M., and Huguet, K. 2014. De-coupling seasonal changes in

346 water content and dry matter to predict live conifer foliar moisture content. Int. J.

347 Wildland Fire, 23(4), 480-489. doi:10.1071/WF13127

348 Jördens, C., Scheller M., Breitenstein B., Selmar D., and Koch, M. 2009. Evaluation of

349 leaf water status by means of permittivity at terahertz frequencies. J. Biol. Phys.

350 35: $255-264$. doi: $10.1007 /$ s10867-009-9161-0

351 Kramer, P.J. 1969. Plant and Soil Water Relationships: A Modern Synthesis. McGraw352 Hill, New York.

353 Liu, P., Yin, L., Deng, X., Wang, S., Tanaka, K., and Zhang, S. 2014. Aquaporin-

354 mediated increase in root hydraulic conductance is involved in silicon-induced

355 improved root water uptake under osmotic stress in Sorghum bicolor L. J. Exp.

$356 \quad$ Bot. 65(17): 4747-4756. doi:10.1093/jxb/eru220.

357 Lösch, R. 2001. Wasserhaushalt der Pflanzen. Quelle \& Meyer, Wiebelsheim, Germany. 
358 Munné-Bosch, S., and Peñuelas, J. (2004). Drought-induced oxidative stress in

359 strawberry tree (Arbutus unedo L.) growing in Mediterranean field conditions.

$360 \quad$ Plant Sci., 166(4), 1105-1110. doi:10.1016/j.plantsci.2003.12.034.

361 Ozkur, O., Ozdemir, F., Bor, M., and Turkan, I. 2009. Physiochemical and antioxidant responses of the perennial xerophyte Capparis ovata Desf. to drought. Environ. Exp. Bot. 66(3), 487-492. doi:10.1016/j.envexpbot.2009.04.003.

364 Rachmilevitch, S., DaCosta, M., and Huang, B. 2006. Physiological and biochemical indicators for stress tolerance. In Plant-environment interactions, 3rd ed. Edited by

Ryser, P., Bernardi J., and Merla, A. 2008. Determination of leaf fresh mass after storage between moist paper towels: constraints and reliability of the method. J. Exp. Bot. 59(9): 2461-2467. doi:10.1093/jxb/ern120.

371

Ryser, P., Gill H.K., and Byrne, C.J. 2011. Constraints of root response to waterlogging in Alisma triviale. Plant Soil 343(1-2): 247-260. doi: 10.1007/s11104-011-0715-0.

372 SanchoØKnapik, D., PeguerōPina J.J., Medrano H., Fariñas M.D., ÁlvarezロArenas T.G., and GildPelegrín, E. 2013. The reflectivity in the SDband and the broadband ultrasonic spectroscopy as new tools for the study of water relations in Vitis vinifera L. Physiol. Plantarum 148(4): 512-521. doi:10.1111/ppl.12007.

376 Slatyer, R.O. 1962. Internal water balance of Acacia aneura F. Muell in relation to environmental conditions. UNESCO Arid Zone Research 16: 137-146.

378 Smart, R.E., and Bingham, G.E. 1974. Rapid estimates of relative water content. Plant Physiol. 53(2): 258-260. Available from 

February 2015].

382 Stocker, O. 1929. Das Wasserdefizit von Gefässplanzen in verschiedenen Klimazonen.

$383 \quad$ Planta 7: 382-387. Available from http://link.springer.com/article/10.1007\%2FBF01916035 [accessed 26 February 2015].

Teszlák, P., Kocsis M., Gaál K., and Nikfardjam, M.P. 2013. Regulatory effects of exogenous gibberellic acid $\left(\mathrm{GA}_{3}\right)$ on water relations and $\mathrm{CO}_{2}$ assimilation among grapevine (Vitis vinifera L.) cultivars. Sci. Hortic.-Amsterdam 159:41-51. doi: dx.doi.org/10.1016/j.scienta.2013.04.037.

390 Thameur, A., Ferchichi, A., and López-Carbonell, M. 2014. Involvement of abscisic acid metabolites and the oxidative status of barley genotypes in response to drought. Can J. Plant Sci. 94(8), 1481-1490. doi:10.4141/CJPS-2014-069.

393 Turner, N.C. 1981. Techniques and experimental approaches for the measurement of plant water status. Plant Soil 58(1-3): 339-366. Available from http://link.springer.com/article/10.1007/BF02180062 [accessed 26 February

397 Walter, J., Nagy L., Hein R., Rascher U., Beierkuhnlein C., Willner E., and Jentsch, A. 2001. Do plants remember drought? Hints towards a drought-memory in grasses. Environ. Exp. Bot. 71: 34-40. doi:10.1016/j.envexpbot.2010.10.020.

400 Weatherley, P.E. 1950. Studies in the water relations of the cotton plant. I. The field 401 measurement of water deficits in leaves. New Phytol. 49(1): 81-97. Available 

[accessed 26 February 2015].

404 Yang, S., Li, X., Ma, Y., Sun, X., Yang, Y., and Yang, Y. 2014. Proteome response of 405 wild wheat relative Kengyilia thoroldiana to drought stress. Can. J. Plant Sci.

406 95(1): 1-13. doi:10.4141/CJPS-2014-294.

407 
408 Table 1. Results of repeated measures ANOVA on leaf fresh mass (FM) with 6

409 measurements after storage of 0 h, 3 h, 6 h, 24 h, 48 h, and 96 h (Experiment 1, data

410 arcsine transformed, one outlier removed) and results of ANOVAs of leaf relative water

411 content (RWC), leaf fresh mass to saturated mass ratio (FM/SM), and leaf dry mass to

412 saturated mass ratio (DM/SM) measured after $0 \mathrm{~h}, 24 \mathrm{~h}$ and $96 \mathrm{~h}$ storage in a refrigerator

413 or at room-temperature with time of storage and storage temperature as factorial variables

414 (Experiment 2, seven outliers removed). ANOVAs were conducted for each species

415 separately. F values and the level of significance are given $(* \mathrm{p}<0.01 ; * * \mathrm{p}<0.01 ; * * *$

$416 \mathrm{p}<0.001$, n.s. not significant).

\begin{tabular}{|c|c|c|c|c|c|}
\hline & $\mathbf{N}$ & $\mathbf{R 2}$ & Temperature & Time & Temp x Time \\
\hline \multicolumn{6}{|l|}{ FM, Experiment 1} \\
\hline Impatiens capensis & 20 & & $65.7 * * *$ & $273 * * *$ & $57.3 * * *$ \\
\hline Alnus incana & 19 & & $142 * * *$ & $739 * * *$ & $131 * * *$ \\
\hline Comptonia peregrina & 20 & & 0.0 n.s. & 1.2 n.s. & 1.6 n.s. \\
\hline Scirpus microcarpus & 20 & & $60.3^{* * *}$ & $159 * * *$ & $28.5^{* * *}$ \\
\hline \multicolumn{6}{|l|}{ RWC, Experiment 2} \\
\hline Impatiens capensis & 58 & 0.664 & 1.1 n.s. & $73.4 * * *$ & $10.4^{* *}$ \\
\hline Alnus incana & 59 & 0.179 & 0.8 n.s. & 10.3. ** & 0.2 n.s. \\
\hline Comptonia peregrina & 58 & 0.029 & 1.0 n.s. & 0.6 n.s. & 0.9 n.s. \\
\hline Scirpus microcarpus & 58 & 0.561 & $4.9 *$ & $40.9 * * *$ & $15.0 * * *$ \\
\hline \multicolumn{6}{|l|}{ FM/SM, Experiment 2} \\
\hline Impatiens capensis & 58 & 0.67 & 1.3 n.s. & $73.9 * * *$ & $11.2 * *$ \\
\hline Alnus incana & 59 & 0.141 & 1.0 n.s. & $7.5 * *$ & 0.4 n.s. \\
\hline Comptonia peregrina & 58 & 0.04 & 1.6 n.s. & 0.6 n.s. & 1.6 n.s. \\
\hline Scirpus microcarpus & 58 & 0.552 & $5.0 *$ & $40.3 * * *$ & $14.6 * * *$ \\
\hline \multicolumn{6}{|l|}{ DM/SM, Experiment 2} \\
\hline Impatiens capensis & 58 & 0.154 & 2.9 n.s. & 2.9 n.s. & $5.6 *$ \\
\hline Alnus incana & 59 & 0.286 & 2.6 n.s. & $16.1 * * *$ & $4.5 *$ \\
\hline Comptonia peregrina & 58 & 0.159 & $7.6 * *$ & 0.2 n.s. & $9.8 * *$ \\
\hline Scirpus microcarpus & 58 & 0.055 & 1.1 n.s. & 0.1 n.s. & 0.2 n.s. \\
\hline
\end{tabular}


419 Fig. 1. Leaf fresh mass of the four investigated species after storage times from 3 to $96 \mathrm{~h}$,

420 stored in a refrigerator (light symbols) or at room temperature (dark symbols). The values

421 are normalized to the directly measured initial mass. The error bars indicate $\pm 1 \mathrm{SE}$.

422

423 Fig. 2. Leaf relative water content (RWC), leaf fresh mass to saturated mass ratio

424 (FM/SM), and leaf dry mass to saturated mass ratio (leaf dry matter content; LDMC) for

425 the four investigated species, measured after $0 \mathrm{~h}, 24 \mathrm{~h}$ and $96 \mathrm{~h}$ storage in a refrigerator

426 (light grey bars) or at room-temperature (dark grey bars).

427 


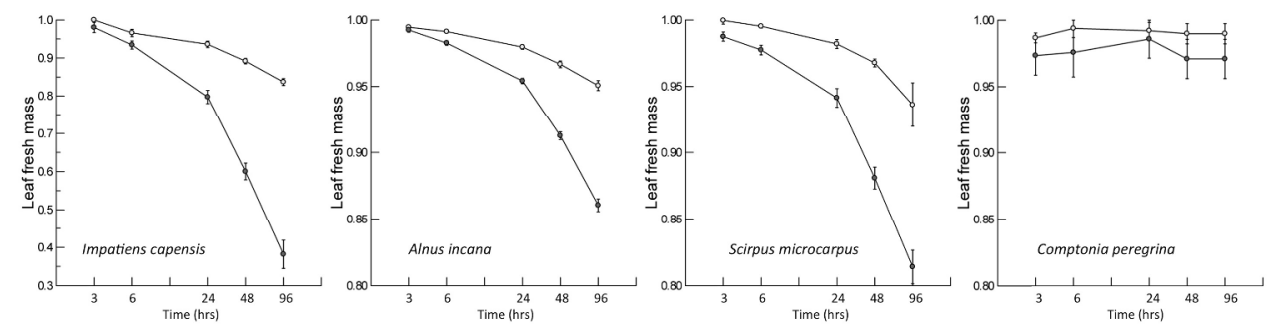

Fig. 1. Leaf fresh mass of the four investigated species after storage times from 3 to $96 \mathrm{~h}$, stored in a refrigerator (light symbols) or at room temperature (dark symbols). The values are normalized to the directly measured initial mass. The error bars indicate $\pm 1 \mathrm{SE}$. $1057 \times 251 \mathrm{~mm}(300 \times 300$ DPI $)$ 

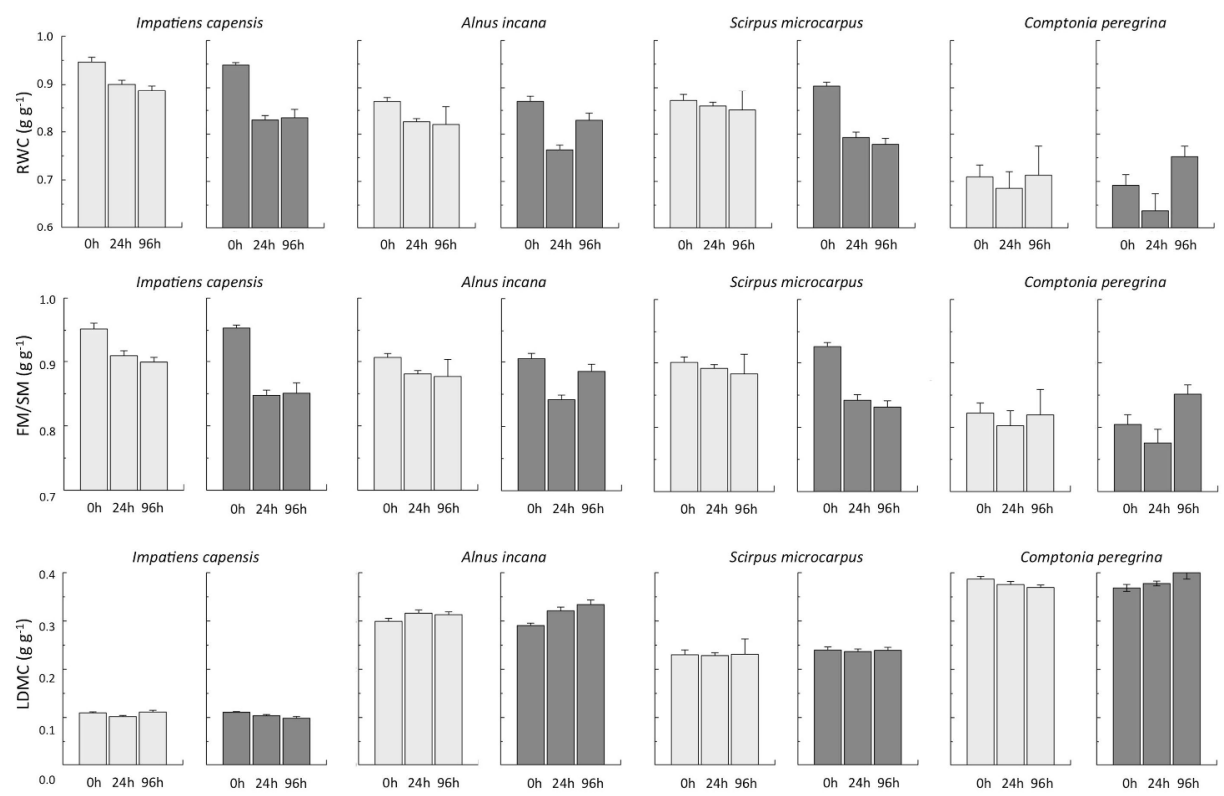

$257 \times 185 \mathrm{~mm}(300 \times 300$ DPI $)$ 